\title{
Advances in Red VCSEL Technology
}

\section{Klein Johnson, Mary Hibbs-Brenner, William Hogan, and Matthew Dummer}

\author{
Vixar, 2950 Xenium Lane, Suite 104, Plymouth, MN 55441, USA \\ Correspondence should be addressed to Mary Hibbs-Brenner, mhibbsbrenner@vixarinc.com
}

Received 6 July 2011; Revised 4 November 2011; Accepted 8 November 2011

Academic Editor: Rainer Michalzik

Copyright ( $\odot 2012$ Klein Johnson et al. This is an open access article distributed under the Creative Commons Attribution License, which permits unrestricted use, distribution, and reproduction in any medium, provided the original work is properly cited.

\begin{abstract}
Red VCSELs offer the benefits of improved performance and lower power consumption for medical and industrial sensing, faster printing and scanning, and lower cost, higher speed interconnects based upon plastic optical fiber (POF). However, materials challenges make it more difficult to achieve the desired performance than at the well-developed wavelength of $850 \mathrm{~nm}$. This paper will describe the state of the art of red VCSEL performance and the results of development efforts to achieve improved output power and a broader temperature range of operation. It will also provide examples of the applications of red VCSELs and the benefits they offer. In addition, the packaging flexibility offered by VCSELs, and some examples of non-Hermetic package demonstrations will be discussed. Some of the red VCSEL performance demonstrations include output power of $14 \mathrm{~mW}$ CW at room temperature, a record maximum temperature of $115^{\circ} \mathrm{C}$ for $\mathrm{CW}$ operation at an emission wavelength of $689 \mathrm{~nm}$, time to $1 \%$ failure at room temperature of approximately 200,000 hours, lifetime in a $50^{\circ} \mathrm{C}, 85 \%$ humidity environment in excess of 3500 hours, digital data rate of $3 \mathrm{Gbps}$, and peak pulsed array power of greater than $100 \mathrm{~mW}$.
\end{abstract}

\section{Introduction}

Multimode $850 \mathrm{~nm}$ VCSELs based upon the AlGaAs materials system have been the standard optical source for glass fiber optic-based data communication links since the mid-1990s. Although the first demonstration of red VCSELs followed fairly quickly after the demonstration of the industry standard "all-semiconductor" $850 \mathrm{~nm}$ VCSEL, the commercialization of red VCSEL technology has proceeded much more slowly due to the materials limitations that have made the development more challenging.

The AlGaAs materials system which is used for $850 \mathrm{~nm}$ VCSELs provides good lattice matching over the full range of compositions, a reasonably good refractive index contrast between the high index (AlGaAs with approximately 1520\% mole fraction AlAs) and low index (AlAs) materials used for the mirrors, and a high (approximately $0.35 \mathrm{eV}$ ) conduction band offset between the GaAs quantum wells and the AlGaAs compositions normally used as quantum well barriers. However, the 650-700 nm emission wavelength range requires use of GaInP quantum wells with AlGaInP barrier layers, with the compositions limited to those which are nearly lattice matched to a GaAs substrate. The AlGaAs materials system is usually used for the mirrors. Several limitations for these shorter wavelength VCSELs exist: (1) the available conduction band offset is smaller and ranges from approximately $0.17 \mathrm{eV}$ at $650 \mathrm{~nm}$ to $0.23 \mathrm{eV}$ at $700 \mathrm{~nm}$ [1]. Therefore, thermal carrier overflow limits the maximum temperature of operation and peak power, limitations that become more apparent at shorter wavelengths. (2) The requirement that the mirrors be nonabsorbing limits the mirror compositions available to AlGaAs materials with AlAs mole fraction greater than 0.4-0.5. This reduces the available range of refractive index, requiring more mirror periods to achieve the same reflectivity. Furthermore, the $50 \%$ AlGaAs composition has a higher thermal and electrical resistivity than compositions closer to the binary AlAs or GaAs. This results in a higher conversion of input power to heat, and more difficulty in removing heat from the device, resulting in higher junction temperatures. The development of red VCSELs over the past nearly two decades has focused on ameliorating these issues. Since the early 1990s when the initial red VCSEL research was done, several groups have reported performance improvements in peak output power, temperature range of operation, wavelength range, modulation speed, and reliability. Significant strides in developing red VCSELs have been made, and devices are now being implemented in a number of applications. This 
paper will first review the progress that has been made, will then discuss recent developments, and finally discuss some applications of the technology.

\section{Background}

The earliest reports of red VCSEL demonstrations were in 1993 from Sandia National Labs and Chiao Tung University in Taiwan [2, 3]. Some of this work was initially based upon the use of InGaAlP materials for both the quantum well active region and the mirrors, but fairly quickly most researchers adopted a structure that retained the InGaAlPbased quantum well active region, but used AlGaAs materials in the mirrors, all on a GaAs substrate, thus simplifying the challenge of growing lattice-matched structures. The initial devices were limited in output power and temperature range, as might be expected from the earliest demonstrations of a new technology.

Due to the wavelength dependence of the conduction band offset available in the AlGaInP materials system, the peak output power achieved and the temperature range of operation is a strong function of wavelength. A fairly early paper [4] reported $8.2 \mathrm{~mW}$ of maximum multimode output power, and $1.9 \mathrm{~mW}$ of single-mode output power at $687 \mathrm{~nm}$ at room temperature. This device was fabricated using a proton implant process. Several improvements to the red VCSEL structure, including the use of carbon doping in the mirror, graded interfaces in the mirror, separate confinement structure in the active region, an oxide aperture, and the removal of the GaAs contact layer from the aperture resulted in the demonstration of room temperature peak output power of $4 \mathrm{~mW}$ at $650 \mathrm{~nm}$ and $10 \mathrm{~mW}$ at $670 \mathrm{~nm}[5,6]$. Johnson and Hibbs-Brenner reported an output power of $11.5 \mathrm{~mW}$ at $673 \mathrm{~nm}$ at room temperature [7].

The temperature range of operation is also a strong function of wavelength. The first demonstrations of red VCSELs in 1993 required pulsed operation to lase [2, 3]. However, by $1994 \mathrm{CW}$ operation to $45^{\circ} \mathrm{C}$ had been achieved at $670 \mathrm{~nm}$ [8]. Room temperature operation for wavelengths as short as $645 \mathrm{~nm}$ was demonstrated in 1995, although the output power was very low $(0.04 \mathrm{~mW})$ [9]. Calvert et al. [10] reported the continuous wave operation of $670 \mathrm{~nm}$ single-mode devices to a heat sink temperature of $80^{\circ} \mathrm{C}$. Sale et al. [11] also demonstrated CW lasing at $666 \mathrm{~nm}$ over the temperature range from $-180^{\circ} \mathrm{C}$ to $+80^{\circ} \mathrm{C}$. Knigge et al. [5] extended the temperature range by demonstrating $650 \mathrm{~nm}$ VCSELs achieving output powers of $4.3 \mathrm{~mW}$ at room temperature, with lasing to $65^{\circ} \mathrm{C}$, and $10 \mathrm{~mW}$ at $670 \mathrm{~nm}$ (room temperature) with lasing to $86^{\circ} \mathrm{C}$. The temperature range of operation can further be extended by pulsing the devices, with a temperature up to $160^{\circ} \mathrm{C}$ for a $670 \mathrm{~nm}$ device and up to $172^{\circ} \mathrm{C}$ for a $660 \mathrm{~nm}$ VCSEL $[12,13]$.

Efforts have been made to extend the feasible wavelength range of red VCSELs, both to shorter wavelengths $(<650 \mathrm{~nm})$ and to longer wavelengths $(>700 \mathrm{~nm})$. The first red VCSELs reported below $699 \mathrm{~nm}$ actually included wavelengths as short as $639 \mathrm{~nm}$, although they only operated under pulsed conditions [2]. Choquette et al. [9] were able to achieve
$0.25 \mathrm{~mW} \mathrm{CW}$ room temperature emission at $652 \mathrm{~nm}$ and $0.04 \mathrm{~mW}$ CW room temperature operation at $645 \mathrm{~nm}$. Knigge et al. [14] were able to achieve pulsed operation down to $629 \mathrm{~nm}$, although no power was reported, and $2.1 \mathrm{~mW}$ of room temperature CW power at $647 \mathrm{~nm}$. Several groups have reported efforts to extend the VCSEL wavelength into the range from 700 to $740 \mathrm{~nm}$ [15-20]. All of these efforts above $700 \mathrm{~nm}$ have been based upon the AlGaAs materials system for both the mirrors and the active regions. The performance has been limited in output power and maximum temperature of operation. In some cases [1820] the device only operated in pulsed mode at room temperature, while in other results [15-17] the devices did operate $\mathrm{CW}$ at room temperature, but the output power was limited to less than $1 \mathrm{~mW}$.

Reliability data has been fairly limited. An early report on aging and failure analysis performed the testing under fairly unrealistic conditions, that is, current drive that was $3 \mathrm{x}$ past the rollover point, resulting in a junction temperature of around $250^{\circ} \mathrm{C}$ [21]. This is likely to result in a degradation mechanism that is not representative of normal use conditions. Low-temperature testing was performed on $655 \mathrm{~nm}$ VCSELs [22], demonstrating little degradation over 1000 hours at $20^{\circ} \mathrm{C}$ for a $7 \mu \mathrm{m}$ diameter device operated at $2.5 \mathrm{~mA}$, but a $3 \mathrm{~dB}$ degradation in output power after 500 hours at $40^{\circ} \mathrm{C}$. A second report indicated widely varying results at $665 \mathrm{~nm}$, with one wafer remaining fairly stable during life testing at $6 \mathrm{~mA}$ and $100^{\circ} \mathrm{C}$ for 1000 hours, while a second wafer with a different design (the design differences were not described), where it is noted that the resistance is higher and required drive voltage in the range of 5-6 V, failed after 300 hours at the same condition [23]. The device diameter was not reported in this case. The most complete report was published in 2008 [24]. Although the device diameter was not specified, 128 devices were placed on test at 8 different acceleration conditions, ranging from 40 to $85^{\circ} \mathrm{C}$, and current drive of 3,4 , or $5 \mathrm{~mA}$. The devices remained on test for close to 8000 hours. From the multiple acceleration conditions, the authors estimated an empirical failure acceleration model of an Arrhenius dependence on temperature with an activation energy of $0.6 \mathrm{eV}$, and a squared dependence upon current. From this data they estimated time to $1 \%$ failure of several hundred thousand hours for use conditions of $40^{\circ} \mathrm{C}$ and $1.5 \mathrm{~mA}$.

Since one of the main applications for red VCSELs is for data communication over plastic optical fiber, the achievable modulation rate is a key parameter of interest. An early measurement [25] showed a small signal $3 \mathrm{~dB}$ bandwidth of around $2.5 \mathrm{GHz}$ and also demonstrated low error rate large signal modulation at 1 Gbps. A subsequent study with better performing VCSELs measured a $3 \mathrm{~dB}$ bandwidth of $11 \mathrm{GHz}$ [26]. Duggan et al. [24] demonstrated a $3 \mathrm{~dB}$ bandwidth in excess of $3 \mathrm{GHz}$ at bias currents of less than $10 \mathrm{~mA}$. Large signal modulation at $1.25 \mathrm{Gbps}$ was demonstrated over temperatures ranging from -20 to $+60^{\circ} \mathrm{C}$. Transceiver modules and connector systems operating at $1.25 \mathrm{Gbps}$ have been developed for plastic optical fiber-based communication links $[27,28]$. 
Novel approaches for dealing with the limited electrical and thermal conductivity have included the incorporation of transparent indium tin oxide (ITO) contacts that extend across the entire VCSEL aperture [29] and the incorporation of plated copper interconnects around the VCSEL mesa [30]. While the latter approach reduced the thermal resistance, it was postulated that the stress created by the approach prevented improvements in output power and temperature range.

Mode control, that is, for achieving single transverse mode VCSELs, is also a challenge and is typically achieved by reducing the aperture size. Kasten et al. used a photonic crystal approach to achieve single-mode performance [31].

\section{VCSEL Development Approach}

The goals of the work reported here were to increase the output power, temperature range of operation, achievable wavelength range, and reliability of red VCSELs. Specifically, the targets were a minimum of $1 \mathrm{~mW}$ single-mode power from $0-60^{\circ} \mathrm{C}, 10 \mathrm{~mW}$ multimode power up to $40^{\circ} \mathrm{C}$, and at least $1 \mathrm{~mW}$ of useable multimode power at $80^{\circ} \mathrm{C}$. Another goal was to extend performance to $720 \mathrm{~nm}$ with $>1 \mathrm{~mW}$ of useable output power.

The red VCSEL structure is illustrated schematically in Figure 1. The structure is grown on off-axis $4^{\prime \prime} \mathrm{n}+-\mathrm{GaAs}$ substrates. Mirrors are AlGaAs based with graded interfaces between the high and low index layers. The results in this paper come from several different wafers, but in all cases the bottom mirror consisted of between 50 and 56 periods, and the number of top mirror periods ranged from 28 to 36 . The active region consists of 3-5 compressively strained InGaP quantum wells with unstrained or tensile strained AlGaInP barriers and a graded (50-70\%) AlGaInP separate confinement heterostructure (SCH). The p-spacer is doped with $\mathrm{Zn}$. A highly doped contact layer is grown at the top surface to facilitate formation of ohmic contacts.

Current and index confinement is provided by an oxide confinement layer located 2 periods above the quantum well active region. The devices are top-emitting with a ring contact patterned around the current aperture on the front side of the device. The substrate was thinned to $200 \mu \mathrm{m}$ before the deposition of a broad area gold contact on the substrate side of the wafer. A variety of aperture sizes were fabricated to evaluate performance as a function of aperture size. Some die consisted of an array of apertures connected to a common anode in order to increase the total power output per die.

Wafers were probed on an automated probe station with wafer temperature control. $100 \%$ probe testing of the light output and voltage versus drive current $(L-I-V)$ and wavelength was performed. $L-I-V$ measurements were made over a range of temperatures on a sample basis. Devices were mounted on a TO- 46 header for measurement of beam profiles, and for measurement of pulsed characteristics.

Reliability measurements under pulsed conditions were carried out on devices in hermetic TO-46 packages. Resistance to humidity was evaluated at $50^{\circ} \mathrm{C}, 85 \%$ humidity on devices packaged in TO-46 headers but with the glass window removed from the lid. In both cases devices are biased during life testing at the accelerated environmental conditions. However, the devices are removed from the oven at each test point and tested at room temperature and room humidity, which was typically $20-25^{\circ} \mathrm{C}$ and $40 \%$ relative humidity.

\section{Results}

4.1. Temperature Performance. One of the most challenging aspects of designing red VCSELs has been achieving useable output power over the temperature ranges required by the applications of interest. Figure 2 illustrates the temperature performance of two red VCSELs: a single-mode design, emitting at $689 \mathrm{~nm}$ and a multimode design emitting at $693 \mathrm{~nm}$. The single mode device (Figure 2(a)) lases up to $115^{\circ} \mathrm{C}$, with $1 \mathrm{~mW}$ of output power achievable at $75^{\circ} \mathrm{C}$, and $0.5 \mathrm{~mW}$ at $95^{\circ} \mathrm{C}$. (The vertical scale is expanded to allow a closer look at the $L-I-V$ characteristics at the highest temperature.) We believe that this is the highest temperature operation achieved in red VCSELs under CW conditions. Generally, the temperature range of operation of larger diameter devices is more limited. Figure 2(b) illustrates the temperature performance of a multimode $693 \mathrm{~nm}$ VCSEL. This device was tested at increments of $20^{\circ} \mathrm{C}$, and output $1.5 \mathrm{~mW}$ peak power at $80^{\circ} \mathrm{C}$, but ceased lasing between $80^{\circ} \mathrm{C}$ and $100^{\circ} \mathrm{C}$. The improved temperature performance is the result of attention to a number of details, such as mirror design for low thermal and electrical resistance, engineering of the active region, and the proper choice of the gain peak-Fabry-Perot resonance offset. While the longer wavelength of approximately $690 \mathrm{~nm}$ also makes the higher temperature operation easier to achieve due to the larger band discontinuities, the result is still a record temperature even when compared to other results at the same wavelength.

4.2. Single-Mode Performance. Figure 3 further illustrates the performance of single-mode devices at $25^{\circ} \mathrm{C}$. Figure 3(a) overlays the $L-I-V$ curves of an array of single-mode VCSELs. Figure 3(b) shows the beam profile of one of the devices in the array. Profiles in the $x$ - and $y$-direction are taken at three different currents, that is, 4,5 , and $6 \mathrm{~mA}$ and are overlaid in the figure of intensity versus angle. It is difficult to distinguish more than one plot since the three plots overlap so closely. Single spatial mode performance is maintained up to the current corresponding to the peak output power.

4.3. Wafer Uniformity: Wavelength and Device Performance. One of the key questions of interest in the production of devices is the uniformity across a wafer. The wavelength of a VCSEL is approximately proportional to thickness of the layers, so a $1 \%$ variation of thickness can result in approximately a $7 \mathrm{~nm}$ variation in wavelength. In addition, the oxidation diameter can also vary across a wafer due to small differences in layer thickness, doping, or composition. Both of these effects can impact performance of a VCSEL. For instance, the temperature characteristics of a VCSEL depend 


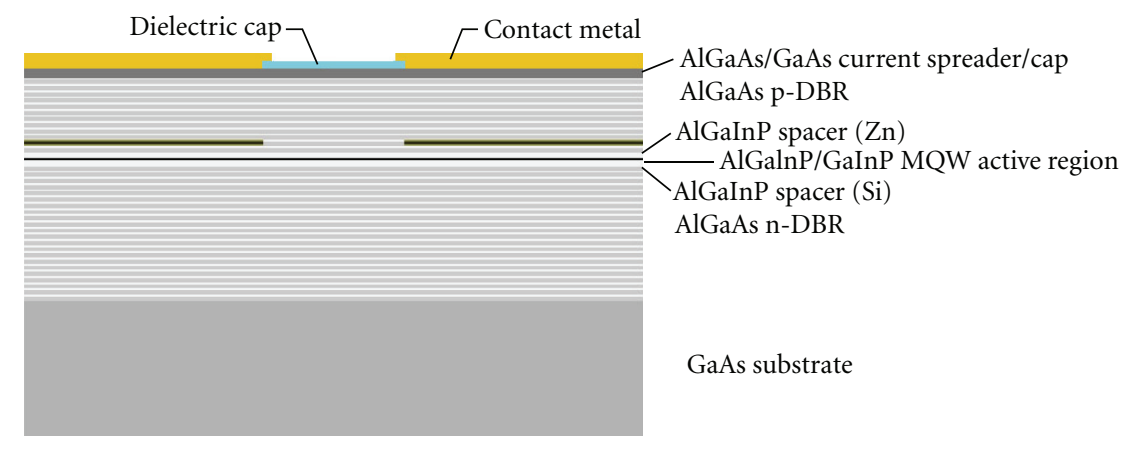

FIGURE 1: Schematic of VCSEL structure (From Proceedings of the SPIE, Vol. 7952, paper 795208).

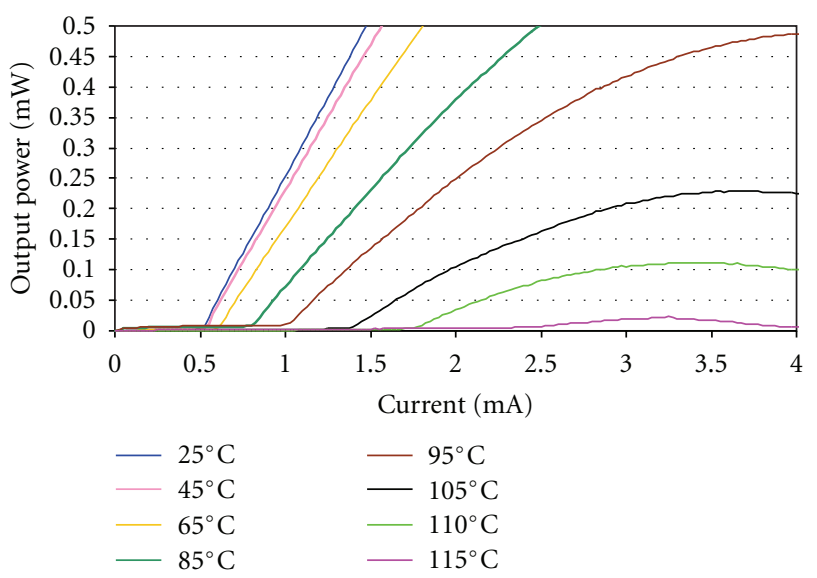

(a)

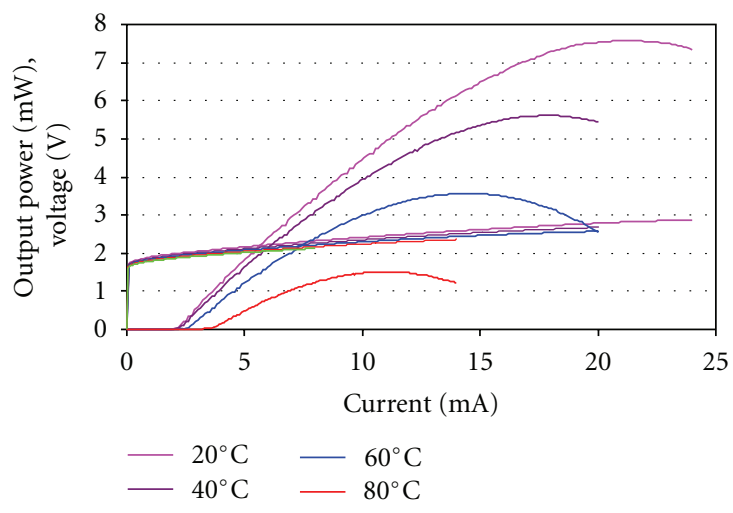

(b)

FIGURE 2: Light output and voltage versus current $(L-I-V)$ at a range of temperatures for (a) a $689 \mathrm{~nm}$ single-mode device, and (b) a $693 \mathrm{~nm}$ multimode device (from Proceedings of the SPIE, Vol. 7952, paper 795208).

upon the offset between the gain peak and the Fabry-Perot resonance. Since the gain peak wavelength is less sensitive to thickness and therefore nearly constant across the wafer, while the Fabry-Perot resonance may have a range of 5$10 \mathrm{~nm}$, this offset varies across the wafer. The ability to do automated wafer scale testing allows us to gather statistics on uniformity.

Figure 4 shows the results of probing approximately 60,000 VCSELs on a $4^{\prime \prime}$ wafer. A histogram of the wavelength distribution of the devices is shown in Figure 4(a). While the distribution ranges from $675 \mathrm{~nm}$ to $709 \mathrm{~nm}$, the vast majority of the devices on the wafer lie in the range from 681 to $692 \mathrm{~nm}$. Figure 4(b) illustrates the uniformity of threshold current as a function of emission wavelength for four different laser aperture sizes. This data (and the data in Figure $4(\mathrm{c})$ ) was taken at $40^{\circ} \mathrm{C}$. The shaded region in the figure corresponds to the wavelength range constituting the majority of the devices on the wafer. Threshold currents are less than $0.5 \mathrm{~mA}$ for the smallest devices and from 1.5 to $2.5 \mathrm{~mA}$ for the $12 \mu \mathrm{m}$ apertures at $40^{\circ} \mathrm{C}$. While the largest diameter devices appear to be quite a bit less uniform than the smallest diameter, on a percentage basis the threshold current range of the $12 \mu \mathrm{m}$ device is similar to that of the 7 and $10 \mu \mathrm{m}$ devices.
As one might expect, the threshold current is U-shaped and rises at the longer wavelengths, due to a larger offset between the gain peak and the Fabry-Perot cavity, but devices are still lasing at $709 \mathrm{~nm}$, where the offset is approximately $40 \mathrm{~nm}$. Peak output power at $40^{\circ} \mathrm{C}$ versus wavelength for several aperture sizes is shown in Figure 4(c). Within the wavelength region included in the shaded region, which includes the majority of the VCSELs on the wafer, the peak output power is quite uniform.

4.4. Maximum Achievable Output Power. Red VCSELs have typically been limited in the maximum output power that can be achieved in part because the larger aperture devices are more sensitive to temperature. Improved design has allowed larger devices to be built. Improvements include the use of quantum well barrier layers with tensile strain to improve the conduction band offset, tailoring of the doping profile in the mirrors to reduce series resistance, and the use of a slightly thicker high aluminum-containing mirror layers, and thinner low aluminum-containing mirror layers (while keeping the sum of the two equal to $\lambda / 2$ ) in each mirror period to improve thermal conductivity. Figure 5 illustrates the $25^{\circ} \mathrm{C}$ output power achievable from two types of devices. Figure 5(a) shows the $L-I-V$ from a single aperture 


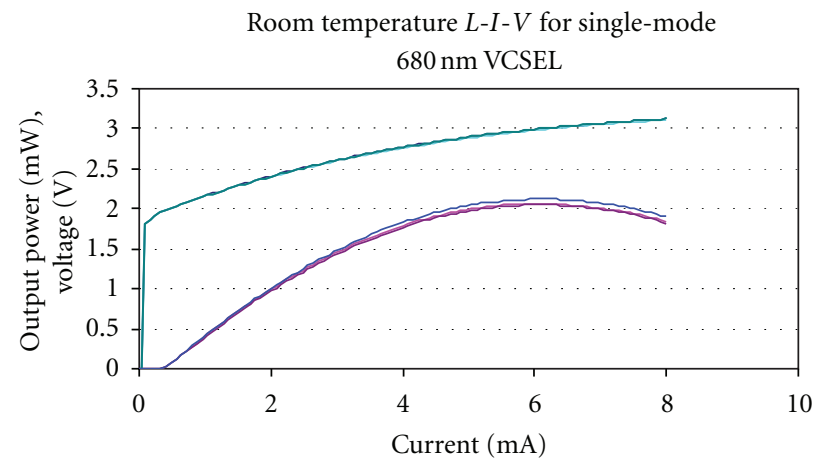

(a)
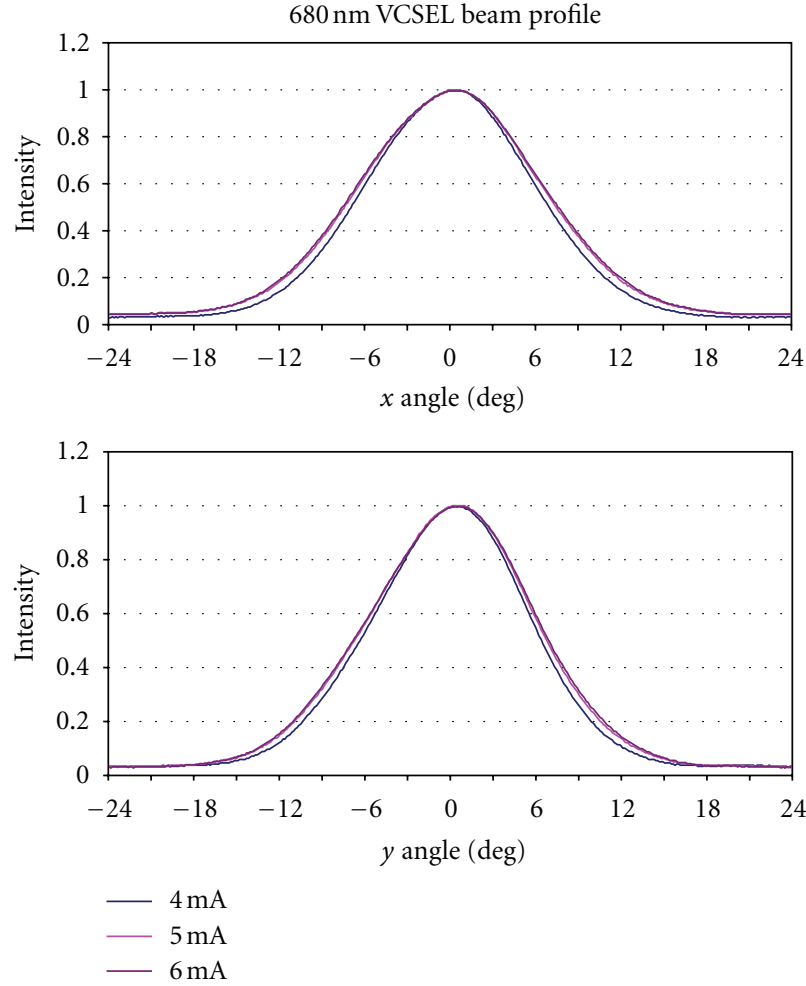

(b)

FIGURE 3: Performance of single-mode $680 \mathrm{~nm}$ VCSELs at $25^{\circ} \mathrm{C}$. (a) Overlaid $L-I$ - $V$ curves from a $1 \times 3$ array. (b) Beam intensity (normalized, arbitrary units) versus angle in the $x$ - and $y$-direction at three current levels: 4, 5, and $6 \mathrm{~mA}$ (from Proceedings of the SPIE, Vol. 7952, paper 795208).

device with a wavelength of $685 \mathrm{~nm}$ which emits a peak output power of $14 \mathrm{~mW}$. If beam size or profile is not an issue, an alternative way of achieving high output power is to use multiple apertures with a common anode contact. Figure 5(b) illustrates that nearly $45 \mathrm{~mW}$ of output power can be generated from a $4 \times 4$ array of apertures emitting at $680 \mathrm{~nm}$ within a $200 \mu \mathrm{m} \times 200 \mu \mathrm{m}$ area.

4.5. Extended Wavelength Performance. We have fabricated devices with wavelengths in the range from 700 to $720 \mathrm{~nm}$, but unlike previous reports [15-20] our devices are based upon GaInP/AlGaInP active regions. A large variation in wavelength across a single wafer was achieved by not rotating the wafer during growth. The gain peak wavelength was fairly constant at around $678 \mathrm{~nm}$, while the Fabry-Perot resonance varied from 680 up to nearly $720 \mathrm{~nm}$. The longest wavelengths, therefore, corresponded to a very large gain peak-resonance offset, as large as $40 \mathrm{~nm}$. Figure 6 shows the results from two devices lasing $\mathrm{CW}$ at $25^{\circ} \mathrm{C}$. A $716 \mathrm{~nm}$ device (Figure 6(a)) had a threshold current of $7 \mathrm{~mA}$ and a peak output power of nearly $3.5 \mathrm{~mW}$, while a $719 \mathrm{~nm}$ device (Figure 6(b)) had a threshold current of $7 \mathrm{~mA}$ and a peak output power of over $2 \mathrm{~mW}$. The threshold current is high due to the large gain peak-resonance offset, so it is believed that even better performance could be achieved if the devices were optimally designed for this wavelength. We therefore believe that good VCSEL performance spanning the entire wavelength range from 650 to $850 \mathrm{~nm}$ can be achieved using either the $\mathrm{AlGaAs}$ materials system, or the AlGaInP materials for the active region.

4.6. Pulsed Operation and Reliability. There are some applications where lasers are typically pulsed at a low duty cycle, such as industrial sensors, or the computed radiography application described in the applications section below. Pulse widths in the range of $1 \mu \mathrm{sec}$ and a duty cycle less than $25 \%$ are common. It has been demonstrated at other wavelengths that the peak output power can be extended significantly due to the reduction in self-heating when pulsed. Red VCSELs are even more limited by thermal effects and hence we desired to quantify the magnitude of potential improvement that could be achieved if the devices were pulsed.

Figure 7 illustrates the performance of a multimode $680 \mathrm{~nm}$ VCSEL operated in pulsed mode. The relevant parameters affecting pulsed performance are pulse width, duty cycle, and ambient temperature. Since $1 \mu \mathrm{sec}$ is a nominal thermal time constant for a VCSEL chip, pulse widths substantially longer than this provide little benefit. We have used $1 \mu$ sec pulse width for the evaluation, although shorter pulse widths can provide even higher peak power. Figure 7(a) illustrates the effect of the duty cycle. A 10\% duty cycle can provide nearly a $4 \mathrm{x}$ improvement in peak power, 


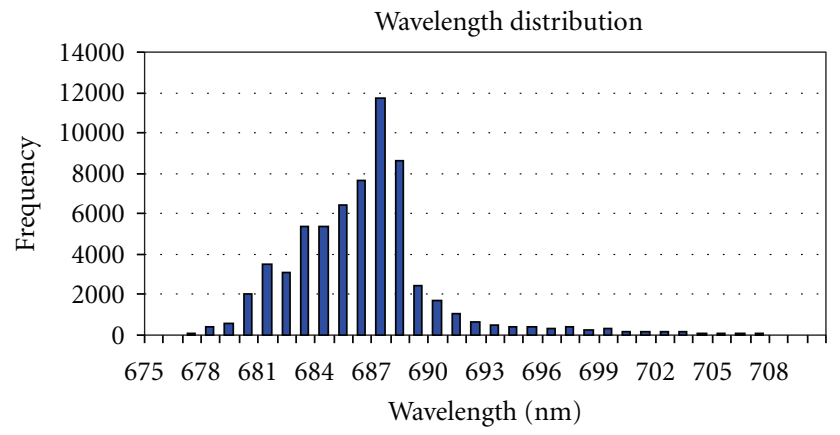

(a)

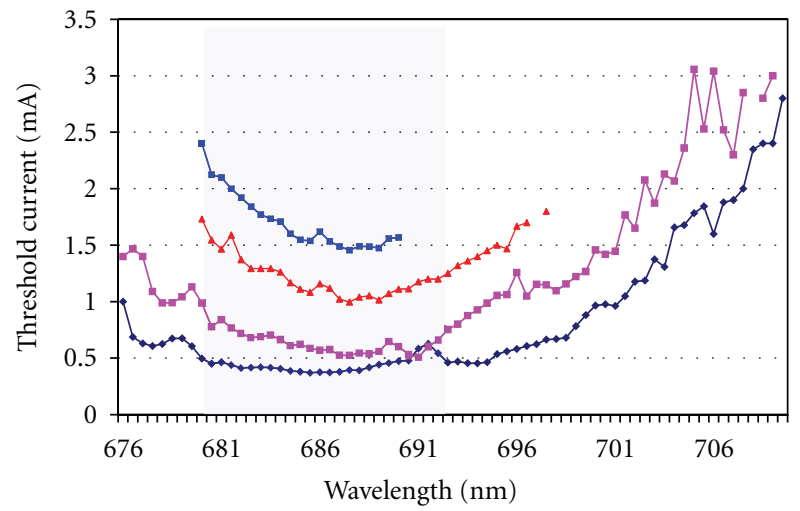

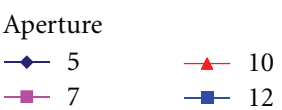

(b)

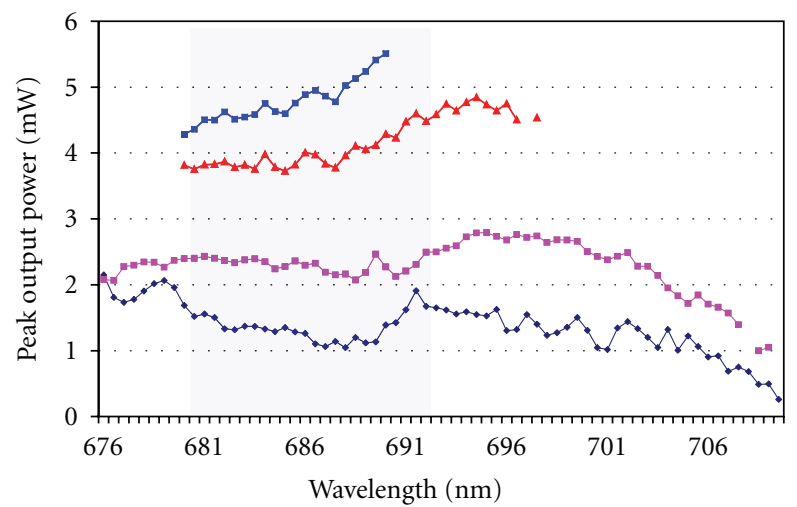

Aperture

$\rightarrow 5 \rightarrow 10$

(c)

FIGURE 4: (a) Histogram showing the wavelength distribution of 60,000 VCSELs tested at $40^{\circ} \mathrm{C}$ on a $4^{\prime \prime}$ wafer. (b) Threshold current versus wavelength. (c) Peak output power versus wavelength. The shaded regions in (b) and (c) indicate the wavelength range corresponding to the vast majority of devices on the wafer (from Proceedings of the SPIE, Vol. 7952, paper 795208).

while a $50 \%$ duty cycle still provides nearly a $2 \mathrm{x}$ increase in peak power. Also note that the peak power achieved at a $10 \%$ duty cycle exceeds $35 \mathrm{~mW}$. This is a multimode device with a single aperture. Figure 7(b) illustrates the improvement in the temperature range of operation that can be achieved when the device is pulsed at a $25 \%$ duty cycle. The peak power of the device at $60^{\circ} \mathrm{C}$ reaches $15 \mathrm{~mW}$, while under $\mathrm{CW}$ operation, the same device might only reach a peak power of 3-4 mW.

Pulsing can also increase the peak output power of the arrays described above. Figure 8 illustrates the benefits of pulsing an array $680 \mathrm{~nm}$ device. The figure demonstrates that 


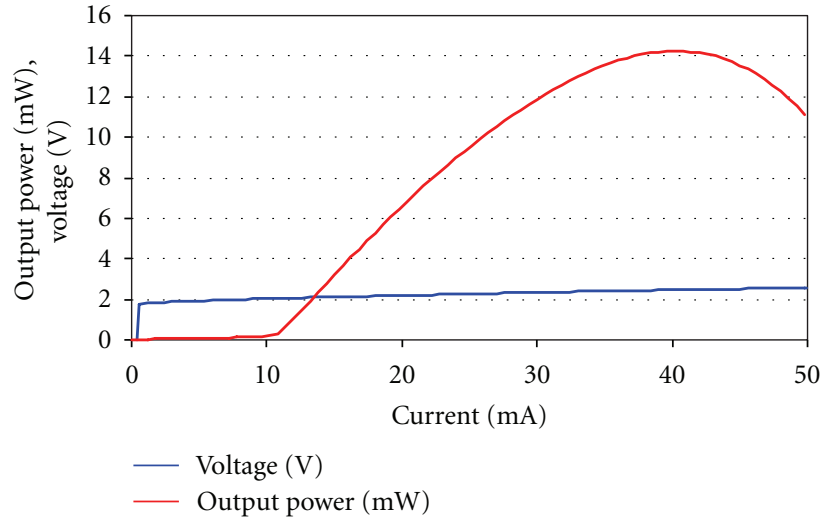

(a)

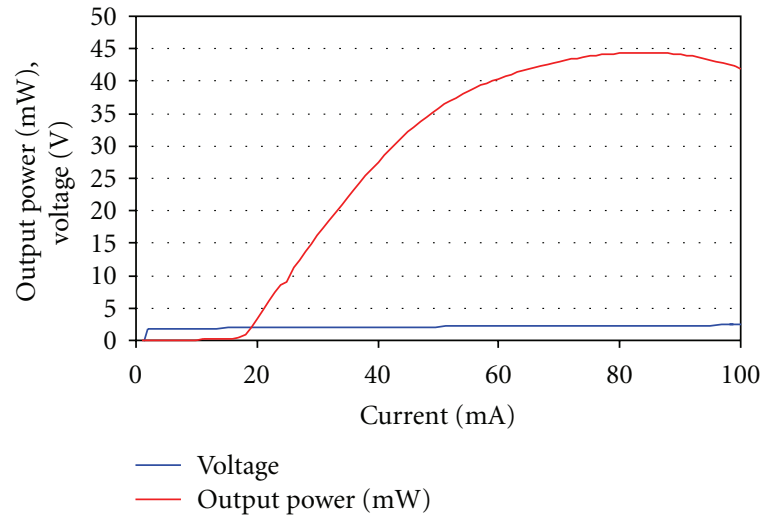

(b)

Figure 5: High output power devices at $25^{\circ} \mathrm{C}$. (a) $L-I-V$ curve from a $685 \mathrm{~nm}$ device with a single large aperture, demonstrating a peak output power of $14 \mathrm{~mW}$. (b) $L-I-V$ from a $680 \mathrm{~nm}$ device with multiple apertures in a $200 \mu \mathrm{m} \times 200 \mu \mathrm{m}$ area, demonstrating a peak output power of $44 \mathrm{~mW}$ (from Proceedings of the SPIE, Vol. 7952, paper 795208).

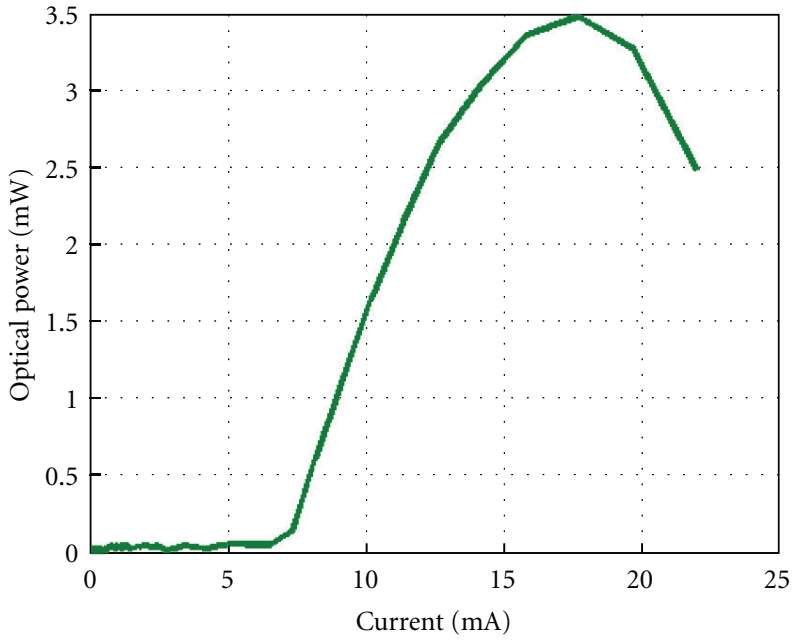

(a)

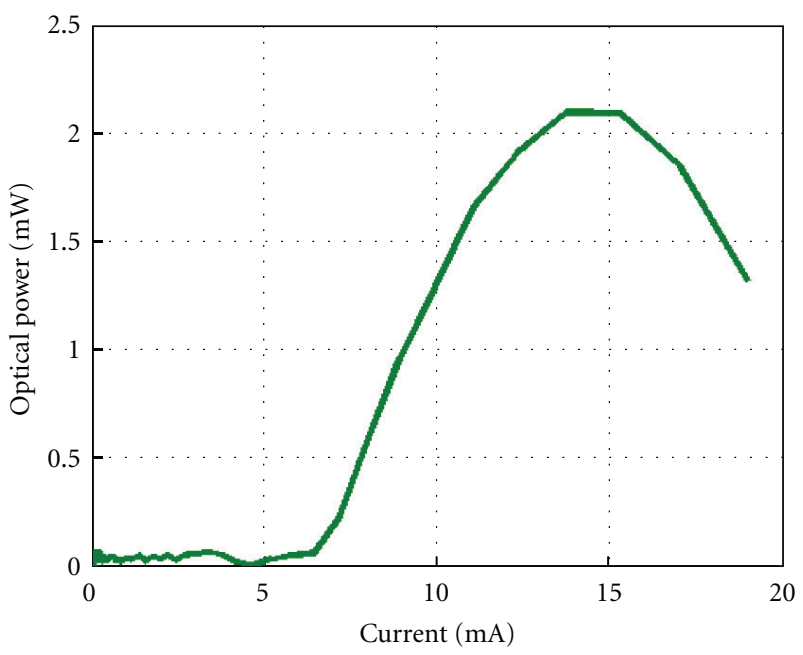

(b)

Figure 6: Performance at $25^{\circ} \mathrm{C}$ of an AlGaInP QW-based VCSEL at (a) $716 \mathrm{~nm}$, and (b) at $719 \mathrm{~nm}$ (from Proceedings of the SPIE, Vol. 7952 , paper 795208).

nearly $120 \mathrm{~mW}$ of peak power can be reached in a $3 \times 3$ array on a single die, using a pulse width of $1 \mu$ sec and a $1 \%$ duty cycle.

In pulsed mode the device self-heating is reduced, and therefore the device rollover point (where increasing the current actually results in a reduction of output power) is extended to significantly higher drive current. However, this leads to a question: if device lifetime is reduced by higher current (or, more accurately, current density) can one operate a device in pulsed mode at these higher current ranges for useful periods of time? Furthermore, are there any transient effects, such as stress created by repeated junction temperature cycling resulting from the current cycling that might actually accelerate the degradation of the devices beyond what is normally expected from the current drive alone? For instance, the VCSEL lifetime is commonly found to be reduced proportionally to the square of the current density. An increase of drive current from $8 \mathrm{~mA}$ to $30 \mathrm{~mA}$ might be expected to reduce the lifetime by a factor of 14 due to current density alone. Under CW conditions, the increase in junction temperature from the higher current adds to the acceleration of failure. Using the empirical model for acceleration of failure, we estimate that a $30 \mathrm{~mA} \mathrm{CW}$ drive current would reduce lifetime by a factor of 500 under CW conditions.

To experimentally evaluate the effect of pulsing on reliability we developed a capability for testing the VCSELs in pulsed mode. Both single-mode and multimode devices were packaged in TO-46 headers and mounted on boards that were placed in ovens. The devices were pulsed with a pulse width of $1 \mu \mathrm{sec}$, and a duty cycle of $12.5 \%$. Thus 8 hours of test time correspond to 1 hour of actual "on-time" The devices were periodically removed from the oven and tested $\mathrm{CW}$ at room temperature, and then returned to the oven 


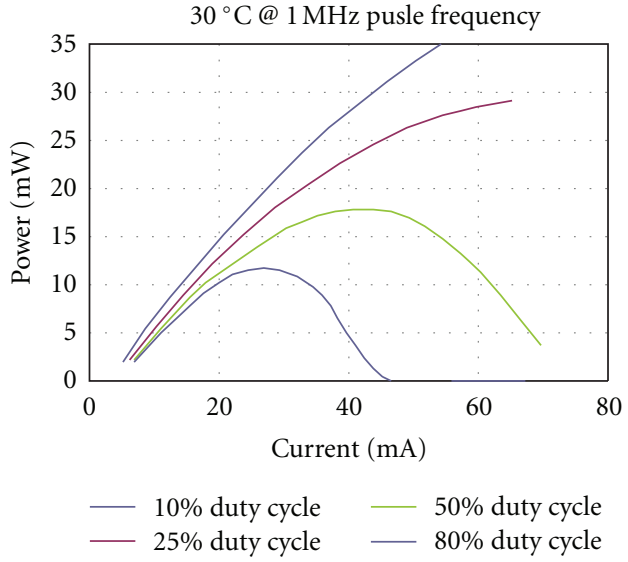

(a)

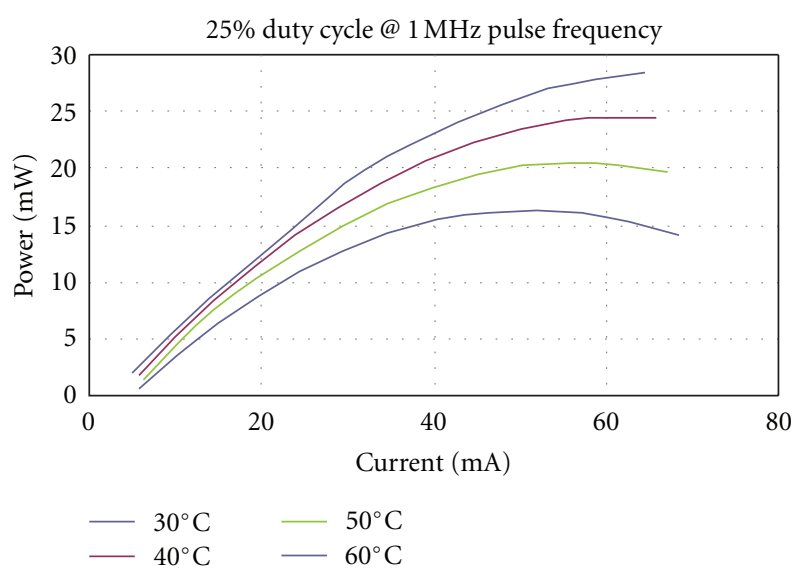

(b)

FIGURE 7: Output power versus current for multimode $680 \mathrm{~nm}$ VCSELs operated in pulsed mode with a $1 \mu$ sec pulse width. (a) illustrates the effect of varying the duty cycle at $30^{\circ} \mathrm{C}$, while (b) illustrates the improved temperature performance associated with pulsed operation (from Proceedings of the SPIE, Vol. 7952, paper 795208).

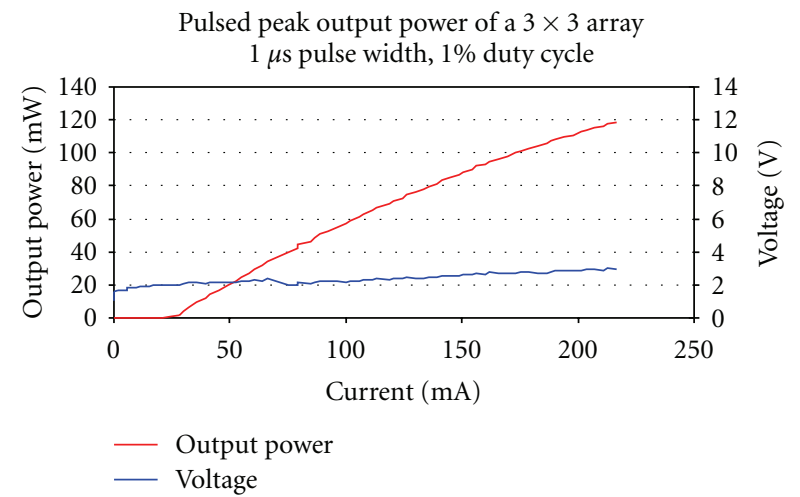

FIGURE 8: An output power of nearly $120 \mathrm{~mW}$ is achieved from a $3 \times 3680 \mathrm{~nm}$ array under pulsed conditions.

for further aging under pulsed conditions. The results are illustrated in Figure 9.

The multimode devices have a CW peak output power around $5 \mathrm{~mW}$ and were pulsed to one of two different current levels, $18 \mathrm{~mA}$ or $30 \mathrm{~mA}$. The single-mode devices have a CW peak output power of approximately 2.5 to $3 \mathrm{~mW}$ and were pulsed to $7 \mathrm{~mA}$. A burn-in effect can be seen in the first 100200 hours, where the output power increases, but after the burn-in period, the output power has been stable during the 6596 hours of test at $50^{\circ} \mathrm{C}$, corresponding to 824 hours of actual pulsed on-time.

Table 1 illustrates the differences in acceleration factor one might expect for the CW and pulsed current cases. In this table we compare acceleration factors based on the assumption of a use condition at $25^{\circ} \mathrm{C}$ and $10 \mathrm{~mA}$. We have measured the thermal resistance of the multimode device, and found it to be $1.4^{\circ} \mathrm{C} / \mathrm{mW}$. We assume acceleration factors which have been reported in [24] for red VCSELs, that is, an Arrhenius relationship for temperature dependence with an activation energy of $0.6 \mathrm{eV}$, and a squared dependence on
Pulsed reliability test, $670 \mathrm{~nm}$ VCSELs $50^{\circ} \mathrm{C}$, pulse width $1 \mu \mathrm{s}, 12.5 \%$ duty cycle $7 \mathrm{~mA}$ (single-mode) 18 and $30 \mathrm{~mA}$ (multimode)

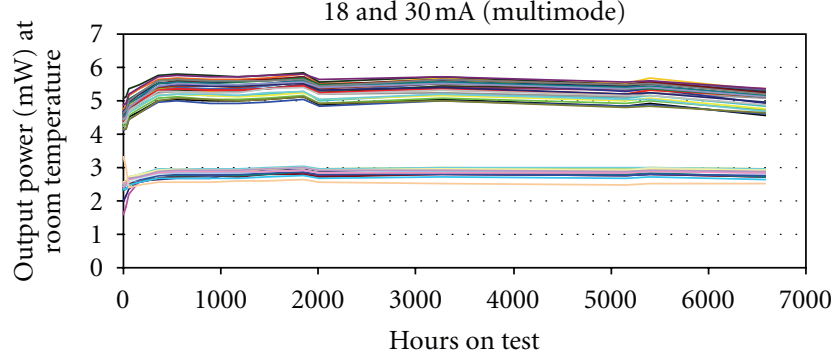

Figure 9: Peak output power versus test time for $670 \mathrm{~nm}$ VCSELS tested in pulsed mode. The output power testing was performed at room temperature. The lower curves correspond to a smaller diameter single-mode device, while the upper curves correspond to a multimode device (from Proceedings of the SPIE, Vol. 7952, paper 795208).

TABLE 1: Calculation of acceleration factors assuming an acceleration temperature of $50^{\circ} \mathrm{C}$ and a use condition of $10 \mathrm{~mA}$ and $25^{\circ} \mathrm{C}$.

\begin{tabular}{lcc}
\hline DC or pulsed & Acceleration current & Acceleration factor \\
\hline \multirow{2}{*}{ DC } & 10 & 4.5 \\
& 18 & 88 \\
& 30 & 2438 \\
\multirow{2}{*}{ Pulsed } & 10 & 6 \\
& 18 & 20 \\
& 30 & 55 \\
\hline
\end{tabular}

current. These acceleration factors are also representative of that routinely reported for $850 \mathrm{~nm}$ VCSELs. We also assumed a thermal resistance of 0 in the pulsed case, that is, that the junction temperature does not rise above ambient. This assumption may not be completely accurate, but it helps 
to define the range of acceleration factors that might be expected.

While we do not yet have sufficient failures to project a lifetime, this table predicts a very significant improvement in lifetime under pulsed conditions, assuming no transient effects, which is consistent with our observations. We would certainly expect devices operated $\mathrm{CW}$ at $30 \mathrm{~mA}$ at $50^{\circ} \mathrm{C}$ for the equivalent of 824 hours (6596 test hours times the $12.5 \%$ duty cycle) to have failed. The lack of failures also prevents us from completely ruling out acceleration due to thermal transients when operated under pulsed conditions, but the lack of degradation observed in Figure 9 suggests that this is not a significant consideration. During 6596 test hours, at a period repetition period of $8 \mu \mathrm{sec}$, the devices have experienced approximately $3 e^{12}$ pulses.

More conventional reliability testing is carried out under conditions of constant current drive. Temperature and current are the most commonly assumed acceleration factors, with humidity being an acceleration factor for devices in non-Hermetic packages. We performed evaluation of VCSELs under dry conditions by placing 186 multimode devices on test at three different temperatures and currents, and periodically removed the devices from the ovens to test output power at room temperature. Failure was defined as a $3 \mathrm{~dB}$ reduction in output power as compared to the output power at time zero. Devices were aged at $50^{\circ} \mathrm{C}$, $85^{\circ} \mathrm{C}$, and $105^{\circ} \mathrm{C}$, and 7,11 , and $15 \mathrm{~mA}$ of drive current. By assuming the same failure acceleration model described above, we calculated the acceleration factor for each of the test conditions relative to a use condition of $40^{\circ} \mathrm{C}$ and a current drive of $8 \mathrm{~mA}$. We then created a "meta-analysis" of the failures by translating the time to each failure at its test condition to the equivalent time at $40^{\circ} \mathrm{C}$ and $8 \mathrm{~mA}$. The results are shown in the plot in Figure 10, below. It can be seen from the figure that the time to $1 \%$ failure is nearly 200,000 hours, or more than 20 years.

Since some applications require a nonhermetic package, and most active optical devices are sensitive to a humid environment, it is important to understand the acceleration of failures due to exposure to humidity. We have performed environmental testing on our chips under accelerated conditions of temperature and humidity. Five chips were packaged in a TO can with the window removed and placed on boards in a chamber held at $50^{\circ} \mathrm{C}$ and $85 \%$ humidity. During aging they were driven continuously with $5 \mathrm{~mA}$ of drive current. The parts were periodically removed from the environmental chamber, and $L-I-V$ curves tested at room temperature and approximately $30-40 \%$ humidity, and the maximum output power recorded. The performance is summarized in Figure 11. After more than 3500 hours, all five devices still demonstrate stable output power.

4.7. Applications. The target applications for red VCSELs fall outside of the existing data communication market where the vast majority of VCSELs have been applied. VCSELs can bring unique value to medical sensor and diagnostic devices, office equipment such as laser printing, industrial sensors, and low cost communications based upon plastic optical

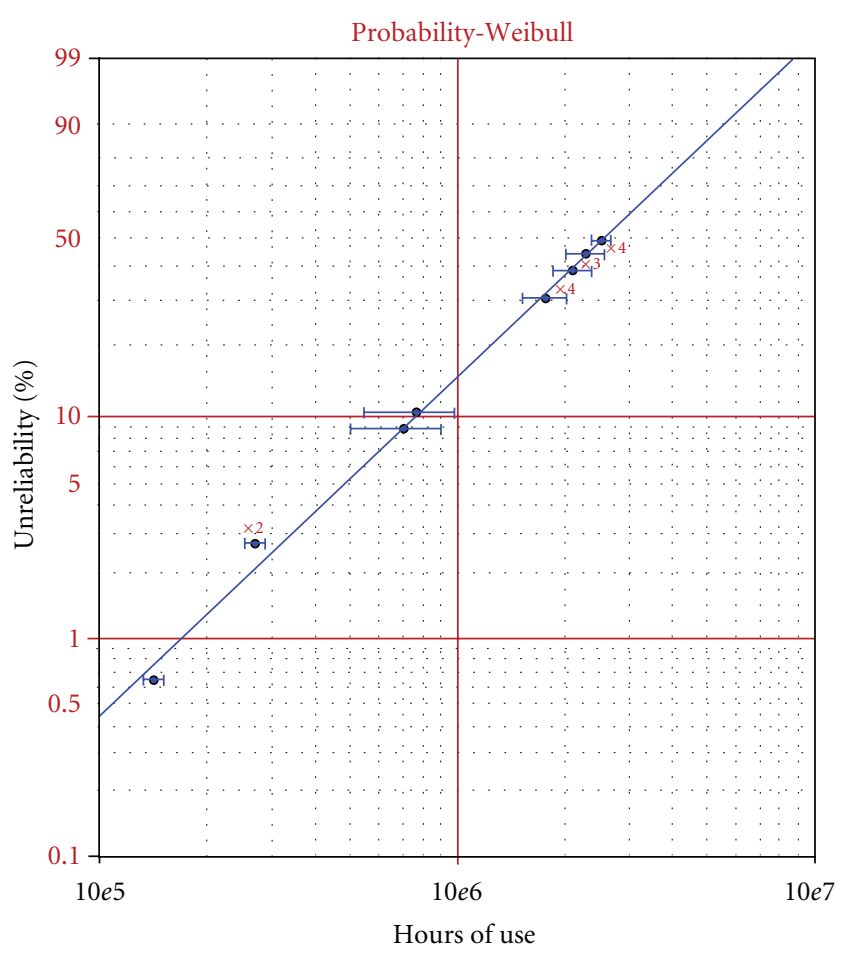

Figure 10: A plot of the failures times of the devices from our reliability evaluation of $670 \mathrm{~nm}$ multimode devices translated to their equivalent failure times at the use condition of $40^{\circ} \mathrm{C}$ and $8 \mathrm{~mA}$. The $y$-axis is the percentage of devices that have failed. Time to $1 \%$ failure occurs at nearly 200,000 hours.

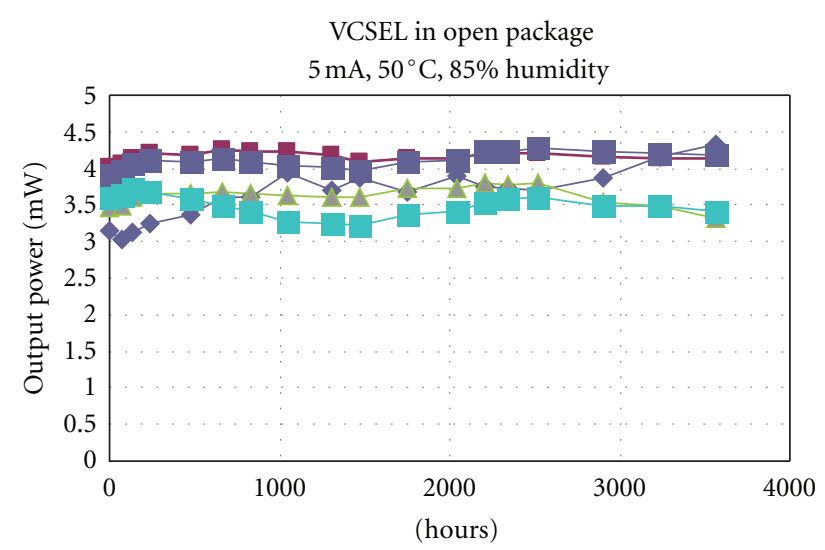

Figure 11: Output power versus hours on accelerated life testing for $690 \mathrm{~nm}$ VCSELs. Devices were maintained at $50^{\circ} \mathrm{C}$ and $85 \%$ humidity and driven with $5 \mathrm{~mA}$ during aging. $L-I-V$ curves were taken at room temperature and room humidity at the test points indicated.

fiber. Design and packaging solutions to address some of these uses are described below.

As a first example, an important optically based noninvasive medical sensor application is oximetry. Pulse oximetry, which measures the oxygen content of arterial blood, is wellestablished using LEDs, while tissue or regional oximetry, 


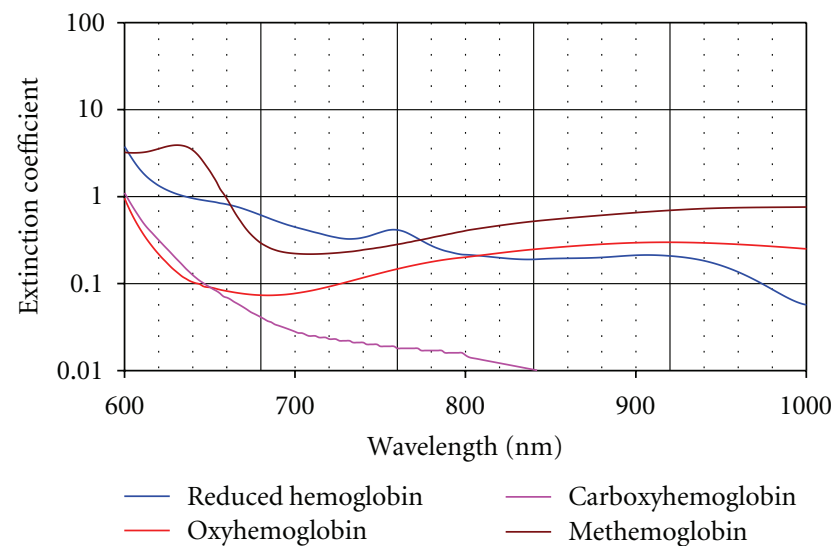

Figure 12: The absorption spectra versus wavelength for four different components of hemoglobin (from http://www.masimo .com/Rainbow/about.htm).

which measures venous or capillary blood, is an emerging application. Near-infrared spectroscopic-based imaging, which relies on differing absorption and scattering as a function of quantity and oxygenation of blood for image contrast, is an active area of research. All versions of oximetry take advantage of the varying absorption coefficient as a function of wavelength for different types of hemoglobins, that is, oxyhemoglobin, reduced hemoglobin, carboxyhemoglobin, or methemoglobin as is illustrated in Figure 12. The sensors rely on the absorption of wavelengths in the range from $650 \mathrm{~nm}$ to $1000 \mathrm{~nm}$, and as the number of blood components one wishes to distinguish increases, the number of different wavelengths that one needs to employ also increases. These applications benefit from the narrow spectral line width and the slow spectral shift with temperature of the VCSEL, while wireless implementations make use of the reduced power consumption of VCSELs as compared to LEDs. In imaging applications, the high speed modulation characteristics of VCSELs are also useful in distinguishing absorption loss from scattering loss.

These sensors are often disposable, body worn sensors requiring a low cost, very compact package that can accommodate multiple chips of various wavelengths. Figure 13(a) illustrates a package that can accommodate multiple devices, potentially of different wavelengths, in a single package. Up to three individually modulated devices can be incorporated, and four devices can be accommodated if they are operated in alternating forward-bias/reverse-bias pairs. Devices are mounted on a lead using conductive epoxy and wire bonded. They are then embedded in an optically clear encapsulant that protects the wire bond and allows the package to be attached to a circuit board via solder reflow. This packaging approach is non-Hermetic, and hence requires the humidity resistance described earlier. Figure 13(b) illustrates the $L-I-$ $V$ (output power and voltage versus current) for the three wavelengths incorporated into a single package. An example of the application of the multiwavelength technology for near-infrared spectroscopic-based brain imaging has been demonstrated at Drexel University [32].
A second example application is plastic optical fiber (POF) links based upon PMMA fiber materials which have been implemented for sensor and data links in automobiles, and are being considered for home networks. PMMAbased fiber has secondary absorption minima in the red. Absorption at $850 \mathrm{~nm}$ is too high for links more than a few meters. While the potential for high speed data rates and the packaging simplicity of VCSELs makes them ideal for this application, wavelengths in the range of $650-680 \mathrm{~nm}$ are a necessity for low loss links. POF links based upon LEDs have been implemented in automobile sensors and entertainment networks. POF links for home networking are being developed and will require data rates in the $1 \mathrm{Gbps}$ range and above at low cost, making VCSELs an attractive solution. Figure 14 illustrates eye diagrams for devices coupled into a 2 meter glass $62 \mu \mathrm{m}$ multimode fiber and modulated at $1.25 \mathrm{Gbps}$ and $3 \mathrm{Gbps}$ with a pseudorandom bit sequence, demonstrating wide open eyes to at least $3 \mathrm{Gbps}$. The measurement of the bandwidth of VCSELs coupled into plastic optical fiber is planned in the near future.

A third application example takes advantage of the ease with which VCSELs can be fabricated in multilaser arrays on a single chip. Vixar has been developing a laser scanner with no moving parts for computed radiography, a form of $\mathrm{X}$-ray imaging that results in a digitized image by storing the X-ray image in a storage phosphor screen, and then reading out the phosphor with a red laser. The red laser stimulates the emission of blue light which is detected and digitized. However, the width of the standard screen, 14 inches, requires a fairly long optical path for scanning with a single laser. A linear laser array could reduce the size of the scanning mechanism and make the equipment more robust. This application requires a wavelength in the 650$700 \mathrm{~nm}$ range. However, creating a linear array of lasers 14 inches long requires tiling array chips in a chip on board configuration.

An early report on this product was published by Dummer et al. [33]. We have since built a 2-inch scanner, pictured in Figure 15, in a much more compact format. The VCSEL array was made up of 16 arrays of $1 \times 32$ VCSELs for a total count of 512 VCSELs. The VCSEL pitch is $100 \mu \mathrm{m}$, which is maintained within a chip and from the edge of one chip to the next. The scanner is operated by pulsing each laser sequentially with a $1 \mu \mathrm{sec}$ wide pulse. A pulsed output power of approximately $8 \mathrm{~mW}$ is achieved for $14 \mathrm{~mA}$ drive current. This assembly is combined with a GRIN lens array to produce focused spots of less than $50 \mu \mathrm{m}$ diameter at a distance of $9 \mathrm{~mm}$ from the top of the GRIN lens array. The total size of the assembly, including GRIN lens array, is $116 \mathrm{~mm} \times 27 \mathrm{~mm} \times 38 \mathrm{~mm}$.

\section{Summary and Conclusions}

The results reported in this paper describe improvements in the temperature range of operation, the magnitude of output power and the range of wavelengths that can be achieved in red VCSELs. The improved performance is the result of attention to many details of the design including 


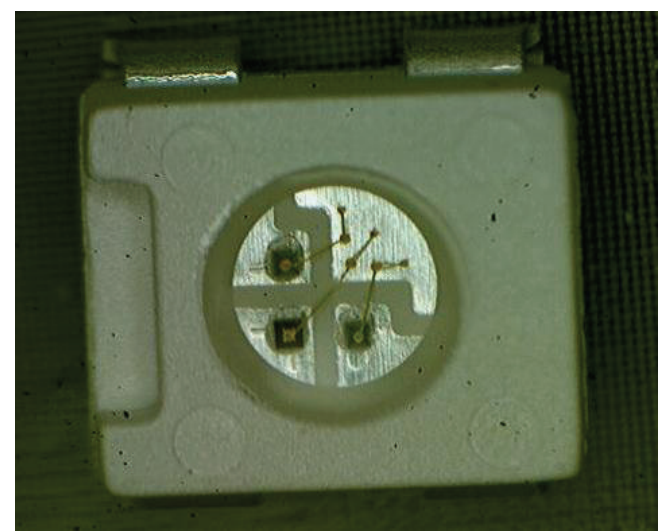

(a)

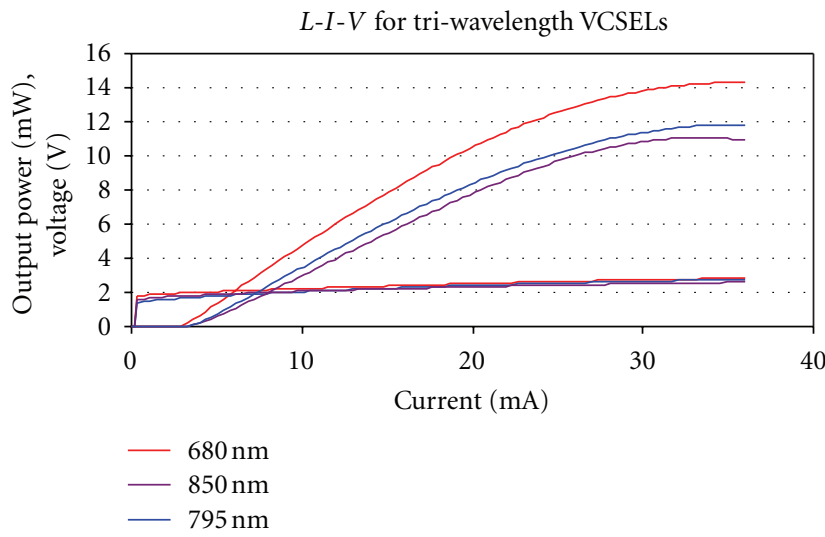

(b)

FIgURE 13: (a) A PLCC package incorporating 3 VCSEL chips. The package dimensions are $2.8 \mathrm{~mm} \times 3.2 \mathrm{~mm}$. (b) Room temperature $L-I$ - $V$ curves for three VCSELs $(680 \mathrm{~nm}, 795 \mathrm{~nm}$, and $850 \mathrm{~nm})$ packaged in a single PLCC-4 package.

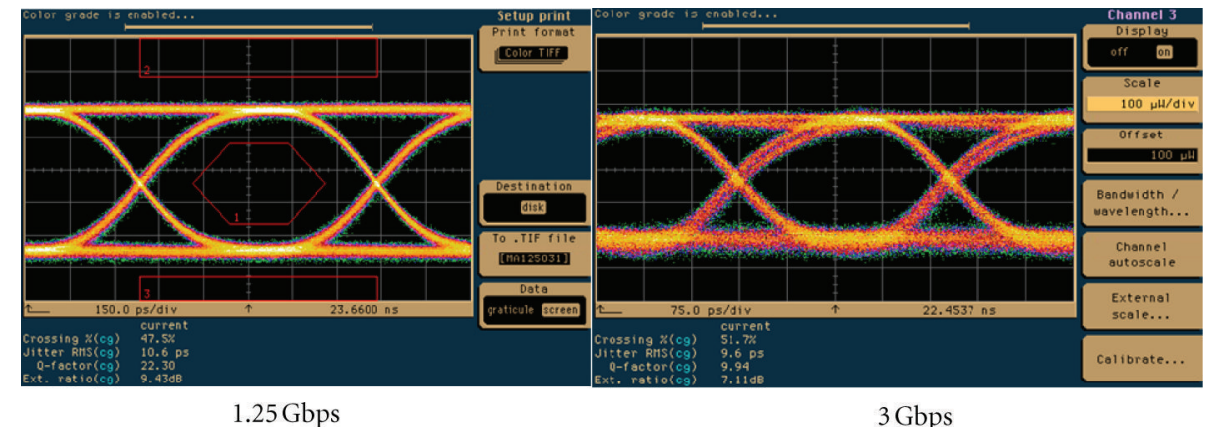

FIGURE 14: Eye diagrams of a pseudorandom bit sequence at $1.25 \mathrm{Gbps}$ (left) and $3 \mathrm{Gbps}$ (right) measured with a Vixar red VCSEL emitting at $670 \mathrm{~nm}$.

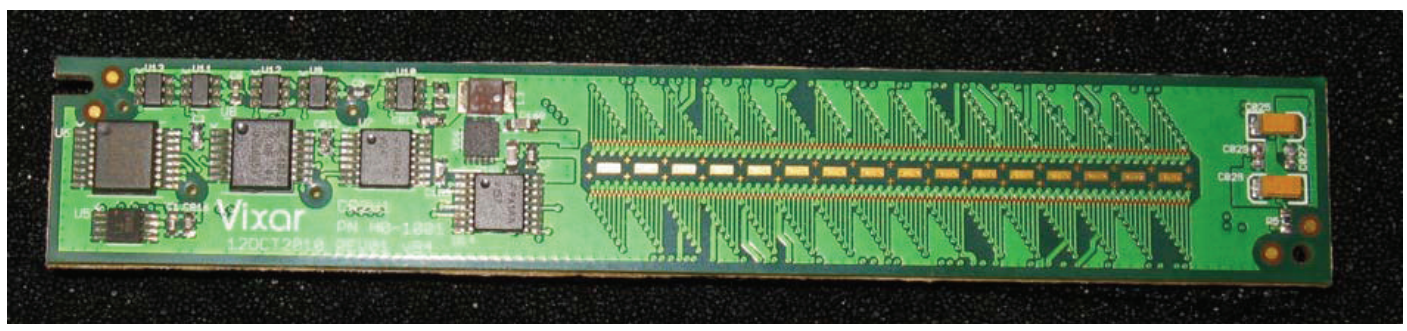

(a)

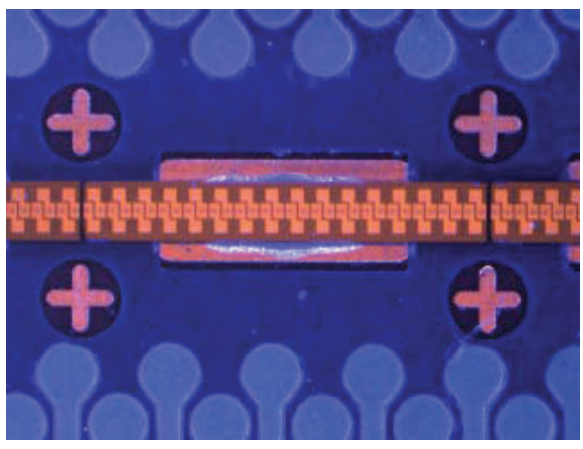

(b)

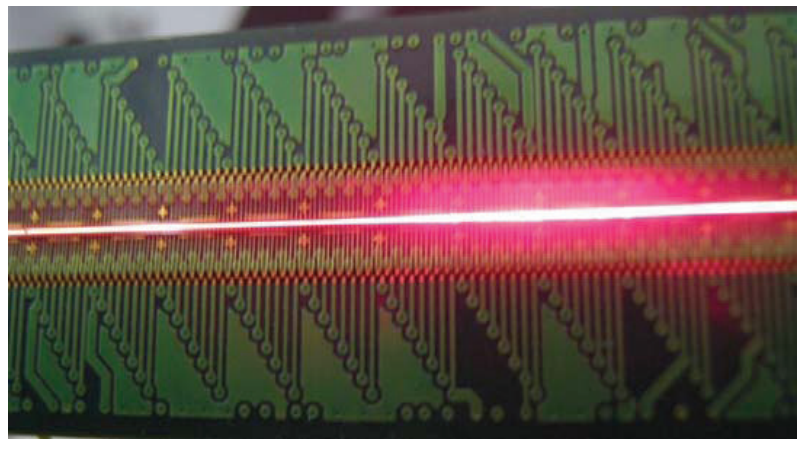

(c)

Figure 15: Photos of the $2^{\prime \prime}$ solid-state scanner. (a) The circuit board including the electronics for controlling the scanner function. (b) A closeup of the board with the VCSEL chips attached but without wire bonding. One full VCSEL array is visible, and the edges of two others. The intersections between chips are between the alignment crosses. (c) A picture of the scanner in operation. 
quantum well active layer design, mirror design, mask layout, proper choice of gain peak resonance cavity offset, and epitaxial materials quality. There is no silver bullet, but the improvement is the result of the accumulation of many incremental steps of optimization.

We have demonstrated red VCSELs lasing at $689 \mathrm{~nm}$ up to $115^{\circ} \mathrm{C}$ for smaller aperture single mode devices. Of more importance is the temperature range of "useable" power. Single mode devices have produced $1 \mathrm{~mW}$ of output power up to $60^{\circ} \mathrm{C}$, and multimode devices provide up to $1.5 \mathrm{~mW}$ of power at $80^{\circ} \mathrm{C} .14 \mathrm{~mW}$ of output power at room temperature has been achieved from a single VCSEL aperture, and as much as $44 \mathrm{~mW}$ of power from a chip containing multiple apertures within a small area.

The range of wavelengths achievable from this materials system has been extended out to $719 \mathrm{~nm}$, with $2 \mathrm{~mW}$ of output power at room temperature at that wavelength. While VCSELs in this wavelength range have been demonstrated in the AlGaAs materials system, the results demonstrate improved output power as compared to the previously reported results. We have not explored the wavelength region below $670 \mathrm{~nm}$ to any substantial degree, but the improvements we have seen at $670 \mathrm{~nm}$ and above, combined with previous reports of devices operating at $650 \mathrm{~nm}$, suggest that operation over a useful power and temperature range at $650 \mathrm{~nm}$ should be feasible. However, operation at wavelengths substantially below $650 \mathrm{~nm}$ with useful power or temperature ranges remains questionable in this materials system.

The benefits of pulsing the VCSEL have been investigated. Peak output power of $35 \mathrm{~mW}$ from one multimode aperture has been demonstrated for a $10 \%$ duty cycle and $1 \mu \mathrm{sec}$ pulse width. Pulsing also allows an extension the temperature range of operation of the VCSELs. Concerns about potential additional acceleration of failure due to repeated thermal transitions have been allayed by reliability data showing stable operation out to nearly 6500 hours when pulsed at $30 \mathrm{~mA}$ and a $12.5 \%$ duty cycle.

A $4^{\prime \prime}$ wafer diameter process and automated wafer probe testing that allows the gathering of statistics on uniformity have been developed. Wavelength uniformity across the wafer is approximately $8 \mathrm{~nm}$, and average threshold current and output power uniformity do not vary significantly within that wavelength range.

The feasibility of using low cost non-Hermetic packages was demonstrated by 3500 hours of continuous operation at $50^{\circ} \mathrm{C}$ and $85 \%$ humidity in a package open to the environment.

Red VCSEL technology has struggled to reach the marketplace due to performance limitations caused by the materials challenges in overcoming thermal and environmental demands. We believe that the results reported here illustrate devices that are ready for use in a wide variety of applications.

\section{Acknowledgments}

This material is based upon work supported by the National Science Foundation under Grant no. IIP-0823022. Any opinions, findings, and conclusions or recommendations expressed in this material are those of the author(s) and do not necessarily reflect the views of the National Science Foundation. The laser scanner work was funded by the National Institutes of Health under Award no. R44RR025874 from the National Center for Research Resources. The content is solely the responsibility of the authors and does not necessarily represent the official views of the National Center for Research Resources or the National Institutes of Health.

\section{References}

[1] W. W. Chow, K. D. Choquette, M. H. Crawford, K. L. Lear, and G. R. Hadley, "Design, fabrication, and performance of infrared and visible vertical-cavity surface-emitting lasers," IEEE Journal of Quantum Electronics, vol. 33, no. 10, pp. 1810$1823,1997$.

[2] J. A. Lott and R. P. Schneider, "Electrically injected visible (639-661 nm) vertical cavity surface emitting lasers," Electronics Letters, vol. 29, no. 10, pp. 830-832, 1993.

[3] K. F. Huang, K. Tai, C. C. Wu, and J. D. Wynn, "Continuous wave visible InGaP/InGaAlP quantum well surface emitting laser diodes," in Proceedings of the Annual Meeting of the IEEE Lasers and Electro-Optics Society, (LEOS'93), pp. 613614, November 1993.

[4] M. H. Crawford, R. P. Schneider Jr., K. D. Choquette, and K. L. Lear, "Temperature-dependent characteristics and singlemode performance of AlGaInP-based 670-690 nm verticalcavity surface-emitting lasers," IEEE Photonics Technology Letters, vol. 7, no. 7, pp. 724-726, 1995.

[5] A. Knigge, M. Zorn, M. Weyers, and G. Tränkle, "Highperformance vertical-cavity surface-emitting lasers with emission wavelength between 650 and 670 nm," Electronics Letters, vol. 38, no. 16, pp. 882-883, 2002.

[6] M. Zorn, A. Knigge, U. Zeimer et al., "MOVPE growth of visible vertical-cavity surface-emitting lasers (VCSELs)," Journal of Crystal Growth, vol. 248, pp. 186-193, 2003.

[7] K. Johnson and M. Hibbs-Brenner, "High output power $670 \mathrm{~nm}$ VCSELs 1648404," in Vertical-Cavity Surface-Emitting Lasers XI, vol. 6484 of Proceedings of SPIE, January 2007.

[8] R. P. Schneider Jr., K. D. Choquette, J. A. Lott, K. L. Lear, J. J. Figiel, and K. J. Malloy, "Efficient room-temperature continuous-wave AlGaInP/AlGaAs visible $(670 \mathrm{~nm})$ verticalcavity surface-emitting laser diodes," IEEE Photonics Technology Letters, vol. 6, no. 3, pp. 313-316, 1994.

[9] K. D. Choquette, R. P. Schneider, M. H. Crawford, K. M. Geib, and J. J. Figiel, "Continuous wave operation of 640-660 nm selectively oxidised AlGaInP vertical-cavity lasers," Electronics Letters, vol. 31, no. 14, pp. 1145-1146, 1995.

[10] T. Calvert, B. Corbett, and J. D. Lambkin, " $80^{\circ} \mathrm{C}$ continuous wave operation of AlGaInP based visible VCSEL," Electronics Letters, vol. 38, no. 5, pp. 222-223, 2002.

[11] T. E. Sale, G. C. Knowles, S. J. Sweeney et al., “- 180 to $+80^{\circ} \mathrm{C}$ CW lasing in visible VCSELs," in Proceedings of the IEEE LEOS Annual Meeting, p. MB5, 2000.

[12] R. Rossbach, R. Butendeich, T. Ballmann et al., " $160^{\circ} \mathrm{C}$ pulsed laser operation of AlGaInP-based vertical-cavity surfaceemitting lasers," Electronics Letters, vol. 39, no. 23, pp. 16541655, 2003. 
[13] M. Eichfelder, R. Roßbach, M. Jetter, H. Schweizer, and P. Michler, "Red high-temperature AlGaInP-VCSEL," in Proceedings of the Conference on Lasers and Electro-Optics, Quantum Electronics and Laser Science, 2007.

[14] A. Knigge, M. Zorn, H. Wenzel, M. Weyers, and G. Tränkle, "High efficiency AlGaInP-based $650 \mathrm{~nm}$ verticalcavity surface-emitting lasers," Electronics Letters, vol. 37, no. 20, pp. 1222-1223, 2001.

[15] H. Q. Hou, K. D. Choquette, B. E. Hammons, W. G. Breiland, M. Hagerott Crawford, and K. L. Lear, "Highly uniform and reproducible visible to near-infrared vertical-cavity surfaceemitting lasers grown by MOVPE," in Vertical-Cavity SurfaceEmitting Lasers, vol. 3003 of Proceedings of SPIE, pp. 34-45, February 1997.

[16] H. Q. Hou, M. H. Crawford, B. E. Hammons, and R. J. Hickman, "Metalorganic vapor phase epitaxial growth of all$\mathrm{AlGaAs}$ visible (700 $\mathrm{nm}$ ) vertical-cavity surface-emitting lasers on misoriented substrates," Journal of Electronic Materials, vol. 26, no. 10, pp. 1140-1144, 1997.

[17] F. Rinaldi, J. M. Ostermann, A. Kroner, and R. Michalzik, "High-performance AlGaAs-based VCSELs emitting in the 760 nm wavelength range," Optics Communications, vol. 270, no. 2, pp. 310-313, 2007.

[18] T. E. Sale, J. S. Roberts, J. Woodhead, J. P. R. David, and P. N. Robson, "Room temperature visible $(683-713 \mathrm{~nm})$ all-AlGaAs vertical-cavity surface-emitting lasers (VCSEL's)," IEEE Photonics Technology Letters, vol. 8, no. 4, pp. 473-475, 1996.

[19] B. Tell, R. E. Leibenguth, K. F. Brown-Goebeler, and G. Livescu, "Short wavelength $(699 \mathrm{~nm})$ electrically pumped vertical-cavity surface-emitting lasers," IEEE Photonics Technology Letters, vol. 4, no. 11, pp. 1195-1196, 1992.

[20] B. Tell, K. F. Brown-Goebeler, and R. E. Leibenguth, "Low temperature continuous operation of vertical-cavity surfaceemitting lasers with wavelength below $700 \mathrm{~nm}$," IEEE Photonics Technology Letters, vol. 5, no. 6, pp. 637-639, 1993.

[21] R. W. Herrick and P. M. Petroff, "Annealing and aging in GaInP-based red VCSELs," in Proceedings of the 10th IEEE Lasers and Electro-Optics Society Annual Meeting, (LEOS'97), pp. 66-67, 1997.

[22] A. Knigge, R. Franke, S. Knigge et al., "650-nm verticalcavity surface-emitting lasers: laser properties and reliability investigations," IEEE Photonics Technology Letters, vol. 14, no. 10, pp. 1385-1387, 2002.

[23] T. E. Sale, D. Lancefield, B. Corbett, and J. Justice, "Ageing studies on red-emitting VCSELs for polymer optical fibre applications," in Proceedings of the IEEE 19th International Semiconductor Laser Conference, pp. 75-76, September 2004.

[24] G. Duggan, D. A. Barrow, T. Calvert et al., "Red vertical cavity surface emitting lasers (VCSELs) for consumer applications," in Vertical-Cavity Surface-Emitting Lasers XII, vol. 6908 of Proceedings of SPIE, January 2008.

[25] D. M. Kuchta, R. P. Schneider, K. D. Choquette, and S. Kilcoyne, "Large- and small-signal modulation properties of RED $(670 \mathrm{~nm})$ VCSEL's," IEEE Photonics Technology Letters, vol. 8, no. 3, pp. 307-309, 1996.

[26] J. A. Lehman, R. A. Morgan, D. Carlson, M. H. Crawford, and K. D. Choquette, "High-frequency modulation characteristics of red VCSELs," Electronics Letters, vol. 33, no. 4, pp. 298-300, 1997.

[27] T. Wipiejewski, G. Duggan, D. Barrow et al., "Red VCSELs for POF data transmission and optical sensing applications," in Proceedings of the 57th Electronic Components and Technology Conference, (ECTC'07), pp. 717-721, June 2007.
[28] T. Wipiejewski, T. Moriarty, V. Hung et al., "Gigabits in the home with plugless plastic optical fiber (POF) interconnects," in Proceedings of the 2nd Electronics Systemintegration Technology Conference, (ESTC’08), pp. 1263-1266, September 2008.

[29] R. Thornton, Y. Zou, J. Tramontana, M. Hagerott Crawford, R. P. Schneider, and K. D. Choquette, "Visible $(670 \mathrm{~nm})$ vertical cavity surface emitting lasers with indium tin oxide transparent conducting top contacts," in Proceedings of the 8th Annual Meeting of the IEEE Lasers and Electro-Optics Society, pp. 108-109, November 1995.

[30] R. Safaisini, K. Johnson, M. Hibbs-Brenner, and K. L. Lear, "Stress analysis in copper plated red VCSELs," Proceedings of the 23rd Annual Meeting of the IEEE Photonics Society, (PHOTINICS '10), pp. 246-247, 2010.

[31] A. M. Kasten, D. F. Siriani, M. K. Hibbs-Brenner, K. L. Johnson, and K. D. Choquette, "Beam properties of visible proton implanted photonic crystal VCSELs," IEEE Journal of Selected Topics in Quantum Electronics, vol. 17, no. 6, pp. 1648$1655,2011$.

[32] E. Sultan, K. Manseta, A. Khwaja et al., "Modeling and tissue parameter extraction challenges for free space broadband fNIR brain imaging systems," in Imaging, Manipulation, and Analysis of Biomolecules, Cells and Tissues IX, vol. 7902 of Proceedings of SPIE, 2011.

[33] M. M. Dummer, K. Johnson, M. Witte, W. K. Hogan, and M. Hibbs Brenner, "Computed radiography imaging based on high-density $670 \mathrm{~nm}$ VCSEL arrays," in Multimodal Biomedical Imaging V, vol. 7557 of Proceedings of SPIE, January 2010. 

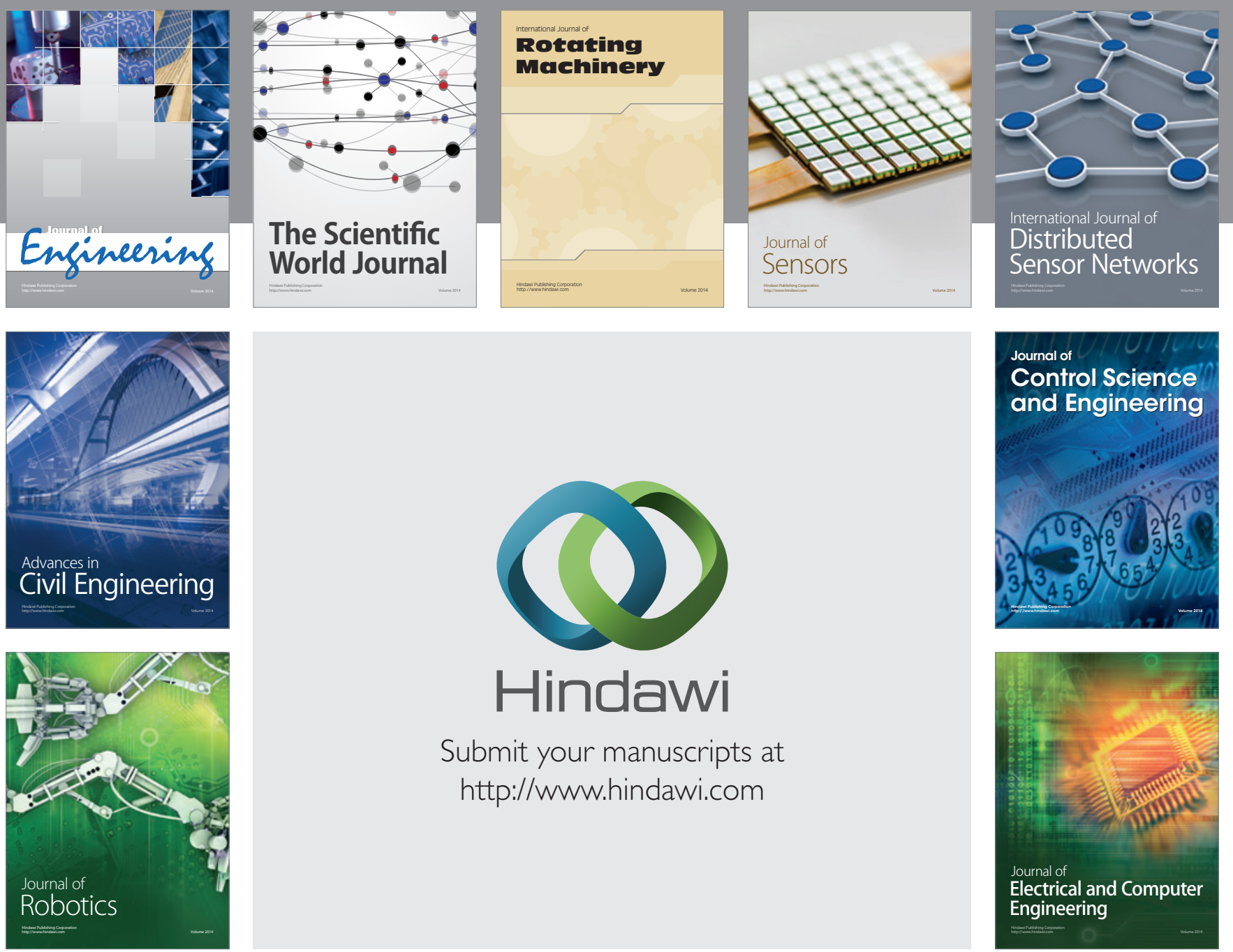

Submit your manuscripts at

http://www.hindawi.com
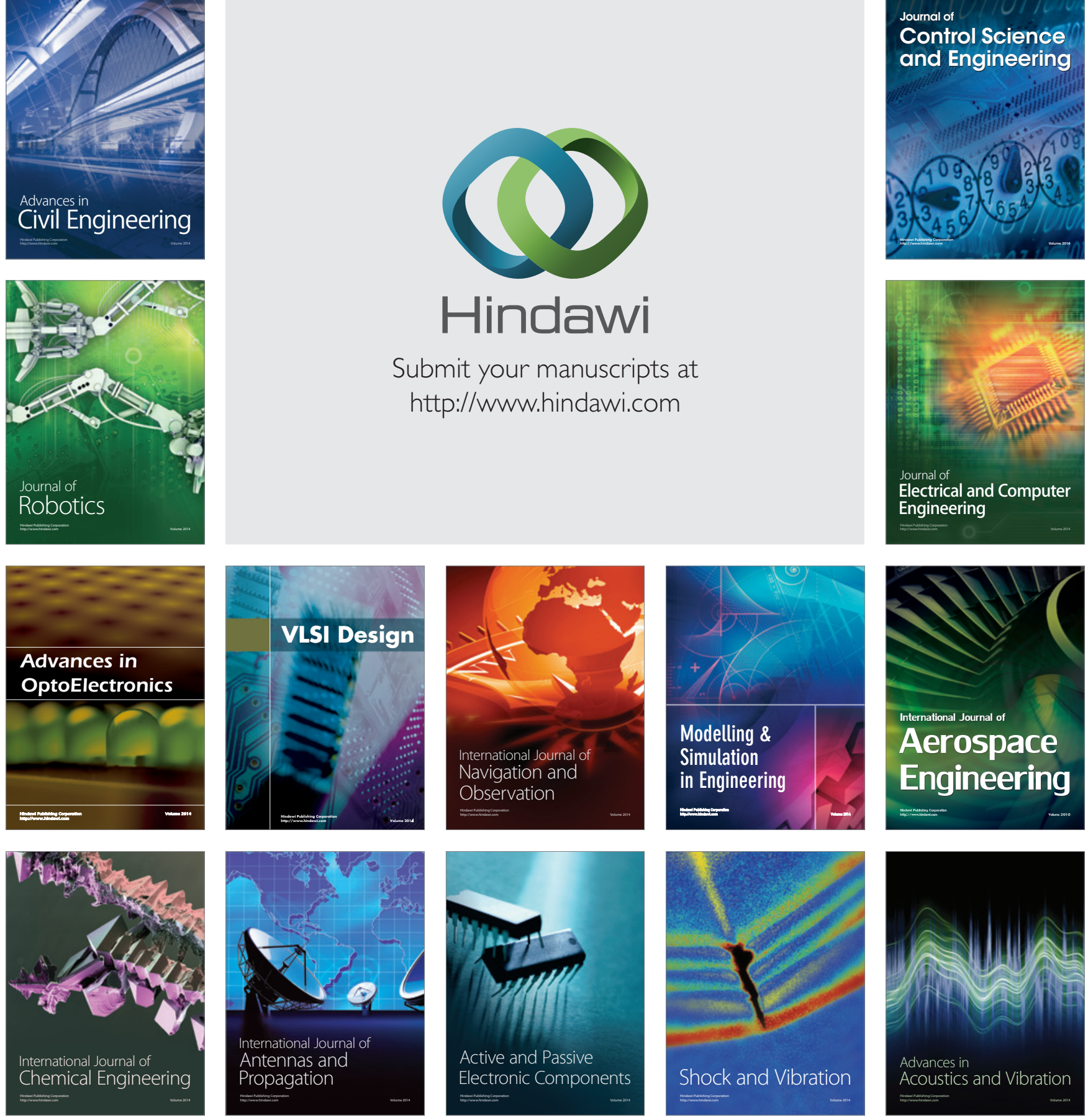